\title{
Comparing costs of microsurgical resection and stereotactic radiosurgery for vestibular schwannoma
}

\author{
Zane Schnurman, MD, MBA, ${ }^{1}$ John G. Golfinos, MD, ${ }^{1}$ David Epstein, MD, ${ }^{1}$ \\ David R. Friedmann, MD, ${ }^{2}$ J. Thomas Roland Jr., MD, ${ }^{2}$ and Douglas Kondziolka, MD1 \\ Departments of ${ }^{1}$ Neurosurgery and ${ }^{2}$ Otolaryngology-Head and Neck Surgery, NYU Langone Medical Center, New York, New \\ York
}

\begin{abstract}
OBJECTIVE Given rising scrutiny of healthcare expenditures, understanding intervention costs is increasingly important. This study aimed to compare and characterize costs for vestibular schwannoma (VS) management with microsurgery and radiosurgery to inform practice decisions and appraise cost reduction strategies.

METHODS In conjunction with medical records, internal hospital financial data were used to evaluate costs. Total cost was divided into index costs (costs from arrival through discharge for initial intervention) and follow-up costs (through 36 months) for 317 patients with unilateral VSs undergoing initial management between June 2011 and December 2015. A retrospective matched cohort based on tumor size with 176 patients (88 undergoing each intervention) was created to objectively compare costs between microsurgery and radiosurgery. The full sample of 203 patients treated with resection and 114 patients who underwent radiosurgery was used to evaluate a broad range of outcomes and identify cost contributors within each intervention group.
\end{abstract}

RESULTS Within the matched cohort, average index costs were significantly higher for microsurgery (100\% by definition, because costs are presented as a percentage of the average index cost for the matched microsurgery group; $95 \%$ $\mathrm{Cl} 93-107)$ compared to radiosurgery $(38 \%, 95 \% \mathrm{Cl} 38-39)$. Microsurgery had higher average follow-up costs $(1.6 \%$ per month, $95 \% \mathrm{Cl} 0.8 \%-2.4 \%$ ) compared to radiosurgery ( $0.5 \%$ per month, $95 \% \mathrm{Cl} 0.4 \%-0.7 \%)$, largely due to costs incurred in the initial months after resection. A major contributor to total cost and cost variability for both resection and radiosurgery was the need for additional interventions in the follow-up period, which were necessary due to complications or persistent functional deficits. Although tumor size was not associated with increased total costs for radiosurgery, linear regression analysis demonstrated that, for patients who underwent microsurgery, each centimeter increase in tumor maximum diameter resulted in an estimated increase in total cost of $50.2 \%$ of the average index cost of microsurgery $(95 \% \mathrm{Cl} 34.6 \%-65.7 \%)\left(p<0.001, R^{2}=0.17\right)$. There were no cost differences associated with the proportion of inpatient days in the ICU or with specific surgical approach for patients who underwent resection.

CONCLUSIONS This study is the largest assessment to date based on internal cost data comparing VS management with microsurgery and radiosurgery. Both index and follow-up costs are significantly higher when tumors were managed with resection compared to radiosurgery. Larger tumors were associated with increased resection costs, highlighting the incremental costs associated with observation as the initial management.

https://thejns.org/doi/abs/10.3171/2018.5.JNS18508

KEYWORDS acoustic neuroma; cost; vestibular schwannoma; skull base surgery; Gamma Knife; stereotactic radiosurgery

$\mathrm{V}$ ESTIBULAR schwannomas (VSs) are benign tumors arising from the Schwann cells of the vestibular branch of the eighth cranial nerve. Patients most often present with progressive unilateral hearing loss, although some report tinnitus, disequilibrium, or vertigo.
Larger tumors can result in other cranial nerve dysfunction or brainstem compression..$^{13,16}$

Management options for VS include observation, microsurgical resection, and irradiation (stereotactic radiosurgery [SRS] being the most commonly used form), but

ABBREVIATIONS BAHA = bone-anchored hearing aid; EMR = electronic medical record; LOS = length of stay; PTA = pure tone average; SDS = speech discrimination score; SRS = stereotactic radiosurgery; VS = vestibular schwannoma.

SUBMITTED February 22, 2018. ACCEPTED May 16, 2018.

INCLUDE WHEN CITING Published online November 9, 2018; DOI: 10.3171/2018.5.JNS18508. 
the best initial approach remains controversial. Clinicians must consider a broad array of factors that impact an individual care recommendation, including patient age, comorbidities, symptoms, hearing status, vestibular function, tumor factors including size and location, and patient preferences. The complex interplay of these factors determines care decisions for individual patients.

Decisions are further complicated by a lack of randomized controlled trials, ${ }^{21}$ requiring physicians to rely on case series or matched cohort reports. ${ }^{3,8,12,19,20,23-25}$ Still, several consistent findings have emerged that inform management of VS. The wait-and-scan or observation approach for treating VS has been found to have lower quality of life outcomes 5 and 10 years after presentation compared to resection and radiosurgery, ${ }^{32}$ and some clinicians think that this option is most appropriate only for patients who are elderly or medically infirm or who have very small tumors. ${ }^{9}$ Reports have consistently documented radiosurgery tumor control rates of $93 \%-100 \%,{ }^{14}$ making radiosurgery a first-line consideration for patients with smaller tumors without major symptomatic brainstem compression. ${ }^{10}$ In these patients, radiosurgery has been found to be better at preserving facial nerve and hearing function with fewer posttreatment complications compared to microsurgery. ${ }^{12,20,24}$

A nonclinical factor that requires consideration is cost. In 2016, US healthcare spending grew by $4.3 \%$, reaching $\$ 3.3$ trillion or $17.9 \%$ of the nation's gross domestic product (GDP) (https://www. cms.gov/Research-Statistics-Data-and-Systems/StatisticsTrends-and-Reports/NationalHealthExpendData/ NationalHealthAccountsHistorical.html). Although these statistics appear abstract, economic studies have demonstrated that workers and households ultimately bear the costs of healthcare through lower wages and higher prices, ${ }^{6}$ representing a real and significant negative effect of rising healthcare costs for the majority of patients.

It may be inappropriate for doctors to prioritize costs when weighing treatment choices for individual patients, ${ }^{15,31}$ but costs must be considered when debating best practices. Calls to constrain healthcare spending will continue to grow, and it is vital that physicians remain active members of this discussion and process to ensure that patient care remains the foremost priority. ${ }^{4}$

Previous studies of VS costs are limited by small sample sizes or do not assess real hospital cost data., 2,,30,35 This study assessed costs associated with initial management of unilateral VS with microsurgery or radiosurgery. It is the largest study to date of VS care that uses real hospital cost data, enabling demographic matching for improved intervention comparisons, and subgroup and outlier analyses to better understand cost drivers. Such findings can contribute to practice considerations and inform cost reduction strategies.

\section{Methods}

\section{Terminology and Financial Data}

For this study, it is important to delineate several financial terms: "charges," "payments," and "costs." Hospital "charges" are individual line items from each hospital's proprietary "chargemaster," which generally reflect inflated list prices used by the hospital as a reference point for payment negotiations. ${ }^{22}$ But these charges are not the amount paid to hospitals. "Payments" are the amount of monies that payers (chiefly private insurers and government) distribute to hospitals for care provided. "Costs" are the expenses paid by the healthcare providers (including hospitals and group practices) to deliver patient care. In this study, only direct provider costs were considered.

Cost data were based on our institution's internal financial data. Internal hospital data probably provide the most detailed and accurate picture of medical expenditures, because hospitals invest considerable resources to best quantify their expenses and thus to enable administrators to make appropriate operational and management decisions. Still, accounting data have limits and drawbacks, including imperfect assumptions and simplifications, ${ }^{33}$ and many institutions limit assessment and public reporting of internal data that are considered proprietary. Specific item costs (i.e., imaging technologies) may be subject to amortization based on device age and procedure volumes unique to that institution, making comparisons among institutions difficult. Per agreement with our institution, costs are reported in relative terms and not in dollars.

\section{Data Collection}

This investigation assessed patients with unilateral VS undergoing initial management with microsurgery or radiosurgery (Fig. 1). The NYU Decision Support System was queried for any patients receiving care under classification codes for "Benign Neoplasm of Cranial Nerve" (ICD-9 225.1 or ICD-10 D33.3) from June 1, 2011 (when the electronic medical records [EMRs] were fully integrated), through December 31, 2015 (to ensure at least 1 full year of follow-up). Data from the Decision Support System were reviewed for these patients, and any who did not have an encounter consistent with SRS or surgery were excluded. All encounters for the remaining preliminary patients were saved (through the end of 2016, when the search was performed, or through 36 months from initial VS intervention), and a detailed chart review was undertaken for each patient. Exclusion criteria included the following: bilateral VS or neurofibromatosis type 2; lesion was found to not be a VS on pathological investigation; or patient had a previous intervention to treat VS.

Through review of EMRs, each individual encounter was confirmed as related or not related to VS care (for example, a screening mammogram would be excluded from further analysis). Demographic data from the medical record, including tumor size (the largest diameter measured in any orientation), surgical approach, patient sex, age, and preoperative hearing status (Gardner-Robertson grade, pure tone average [PTA], and speech discrimination score [SDS]), were documented for each patient.

Any secondary interventions related to VS were noted and costs were included in the analysis. Of note, at our institution, radiosurgery after subtotal resection is either performed early (within 3 to 6 months) or delayed depending on residual tumor volume and surgeon preference. If there is minimal residual tumor, it is more likely to be followed with serial imaging until regrowth is confirmed. 


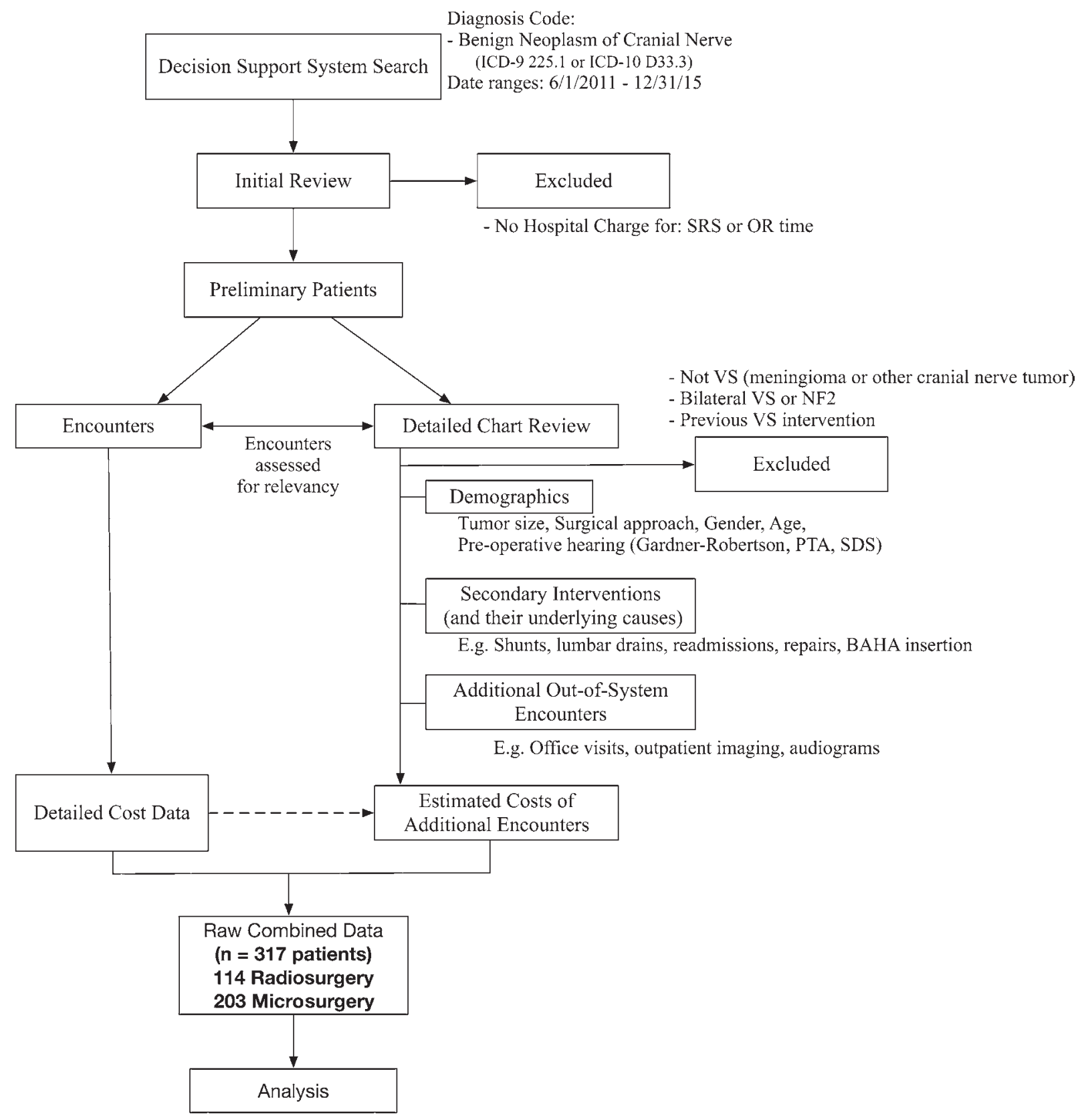

FIG. 1. Diagram of data collection methodology. NF2 = neurofibromatosis type 2; OR = operating room.

Resection after radiosurgery is recommended once clear sustained growth is identified on serial imaging studies, and typically takes several years to document. If there are progressive symptoms from mass effect, a resection may be warranted earlier.

Additional patient encounters referenced in the EMRs or patient notes that occurred outside of our hospital system, including outpatient imaging, office visits, or treatment at other hospital systems, were recorded and included. Costs of these encounters were estimated based on the internal costs for the same encounter type at our institution and based on communications with relevant administrators, including faculty group practice administrators.
For all relevant encounters, detailed internal cost data (listing every line item specified to the administered drug or surgical supply) were downloaded and used for analysis.

\section{Study Populations}

Encounter data from the Decision Support System and chart review were combined to create a database of more than 67,000 individual line items for 317 patients with VS (203 who underwent microsurgery and 114 with radiosurgery).

This population was made into 2 patient samples for analysis. The first sample was a 176-patient matched cohort (88 patients from each intervention group) tailored to 
TABLE 1. Demographics of matched cohort of 176 patients with VS based on tumor size

\begin{tabular}{lccc}
\hline \multicolumn{1}{c}{ Characteristic } & SRS, $n=88$ & MS, $n=88$ & $p$ Value \\
\hline Median age, yrs (range) & $63(29-87)$ & $49(14-72)$ & $<0.001$ \\
\hline $\begin{array}{l}\text { Median tumor size, cm } \\
\text { (range) }\end{array}$ & $1.3(0.6-3.0)$ & $1.3(0.6-3.0)$ & 1.00 \\
\hline Sex (\% female) & $55 \%$ & $67 \%$ & 0.09 \\
\hline Preintervention hearing & & & \\
\hline$\quad$ Gardner-Robertson grade & 2.2 & 1.8 & 0.05 \\
\hline PTA & 40.7 & 35.3 & 0.16 \\
\hline SDS & 66.9 & 67.7 & 0.88 \\
\hline Follow-up (mos) & 24.8 & 26.6 & 0.44 \\
\hline
\end{tabular}

MS = microsurgery

tumor size $( \pm 0.1 \mathrm{~cm})$ to enable appropriate comparison between microsurgery and radiosurgery (Table 1). The second sample included all 317 patients to allow for a robust review of possible outcomes and to assess for factors that significantly impact cost within each intervention group (Table 2).

\section{Data Preparation and Statistical Analysis}

All line items were classified as either an "index cost," which includes any cost incurred from arrival for the initial intervention until discharge, or a subsequent "followup cost." All costs are presented as a percentage of the average index cost for the matched microsurgery group.

All follow-up costs were discounted to the index date to standardize to a present value at a continuous $3 \%$ rate. For a detailed explanation of discounting future cost methodology, see Muennig..$^{17}$ For internal cost data, each distinct unit charge was standardized to the cost determined in the most recently completed fiscal year to prevent confounding from changes in accounting methodology over the study period. Length of stay (LOS), including number of days in an ICU setting, an acute care setting, and inpatient rehabilitation room, and minutes in the operating room for VS resection were extracted from hospital charges.

All statistical analyses were performed using Stata version 14.2 (StataCorp LP). Two-sample t-test, Wilcoxon rank-sum, skewness and kurtosis test for normality, Kruskal-Wallis test, Levene's robust test statistic for the equality of variances, Pearson's correlation $(r=$ Pearson correlation coefficient), and simple linear regression were used.

\section{Results}

\section{Comparison of Radiosurgery and Microsurgery Matched Cohorts \\ Index Costs}

A matched cohort based on tumor size with 176 patients (88 patients from each intervention) was used to compare microsurgery and radiosurgery costs. Demographic details of this cohort are described in Table 1.

Average costs associated with the initial intervention from arrival through discharge, or index costs, were significantly higher for the microsurgical cohort (mean 100\% by definition, SD 32\%, 95\% CI 93-107) compared to the
TABLE 2. Demographics of full patient sample

\begin{tabular}{lccc}
\hline \multicolumn{1}{c}{ Characteristic } & SRS, $\mathrm{n}=114$ & $\mathrm{MS}, \mathrm{n}=203$ & $\mathrm{p}$ Value \\
\hline Median age, yrs (range) & $61(29-87)$ & $48(14-77)$ & $<0.001$ \\
\hline $\begin{array}{l}\text { Median tumor size, } \mathrm{cm} \\
\text { (range) }\end{array}$ & $1.2(0.5-3.0)$ & $1.9(0.6-4.8)$ & $<0.001$ \\
$\begin{array}{l}\text { Sex (\% female) } \\
\text { Preintervention hearing }\end{array}$ & $54 \%$ & $61 \%$ & 0.19 \\
\hline Gardner-Robertson grade & 2.1 & 1.9 & 0.26 \\
\hline PTA & 38.9 & 38.8 & 0.98 \\
\hline SDS & 69.9 & 65.8 & 0.34 \\
\hline
\end{tabular}

radiosurgery group (mean $38 \%$, SD $2 \%, 95 \%$ CI $38-39$ ) $(\mathrm{p}<0.001)$.

Additionally, assessment of the cost distributions found that the microsurgery group had significantly higher index cost variance than radiosurgery ( $\mathrm{p}<0.001$, Levene's test). The microsurgical distribution was significantly positively skewed (skewness 2.4, kurtosis 9.4, p <0.001), whereas the radiosurgery group's index costs demonstrated a normal distribution (skewness 0.1, kurtosis 2.9, $\mathrm{p}=0.93$ ). These findings emphasize that the potential cost ceiling for any individual patient who undergoes microsurgery is significantly higher than for one who receives radiosurgery, even relative to higher average costs.

\section{Follow-Up Costs}

Assessing follow-up costs is inherently challenging given the variability in individual patient follow-up, both in the length of time each patient was followed and in the types of follow-up care each patient received. Of note, there was no significant difference in the average length of time followed between the microsurgery and radiosurgery cohorts (Table 1).

Figure 2A allows visualization of several important characteristics of follow-up in patients with VS. Each line represents an individual follow-up course starting after discharge (month 1) through a maximum of 36 months. The most common postintervention course for both treatment options was standard observation without complications, with office visits and imaging performed at intervals. There was no difference in the mean number of follow-up imaging sessions per month for microsurgery $(0.10)$ and radiosurgery $(0.11, p=0.28)$, indicating that patients in both cohorts underwent scanning approximately once every 9-10 months on average. Comparably, patients treated with microsurgery had more neurosurgical office visits (a mean of 0.14 office visits per month or a visit every 7.1 months on average) compared to those who underwent radiosurgery (a mean of 0.08 visits per month or a visit every 12.5 months on average, $p<0.001$ ). Additionally, patients in the microsurgery subgroup had more office visits to other providers, including otolaryngologist follow-ups, with an average of 0.13 office visits per month (or a visit every 7.7 months on average), compared to the radiosurgery subgroup (a mean of 0.04 visits per month or a visit every 25 months on average, $p<0.001$ ).

As the sporadic spikes in Fig. 2A demonstrate, some patients required secondary interventions, either in re- 


\section{Microsurgery}

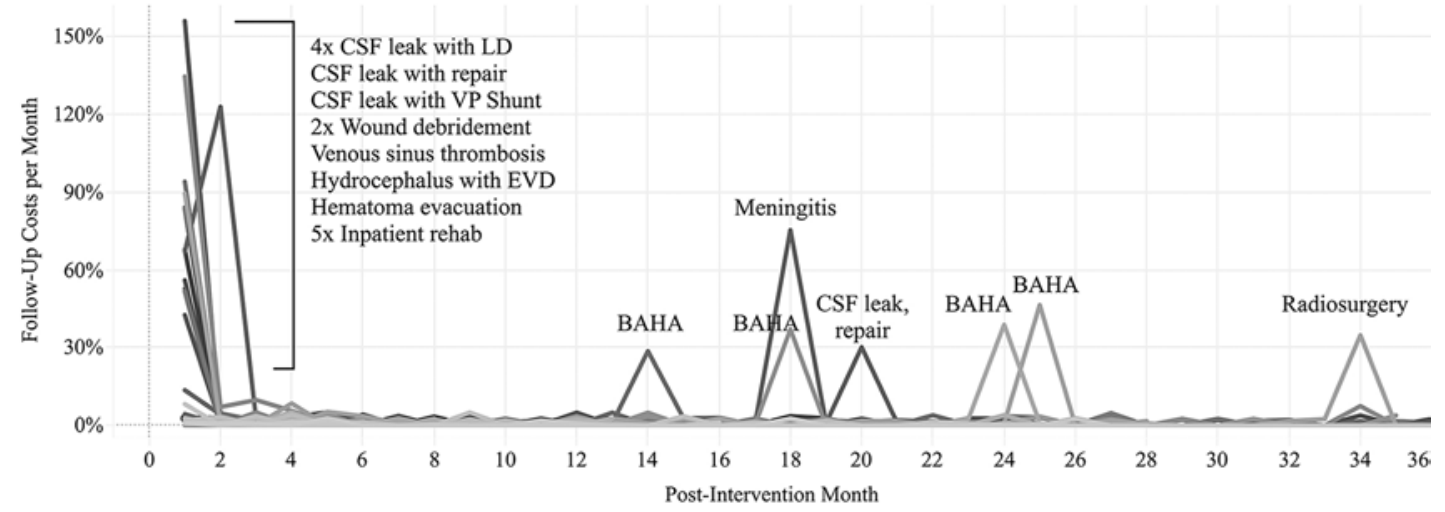

\section{Radiosurgery}
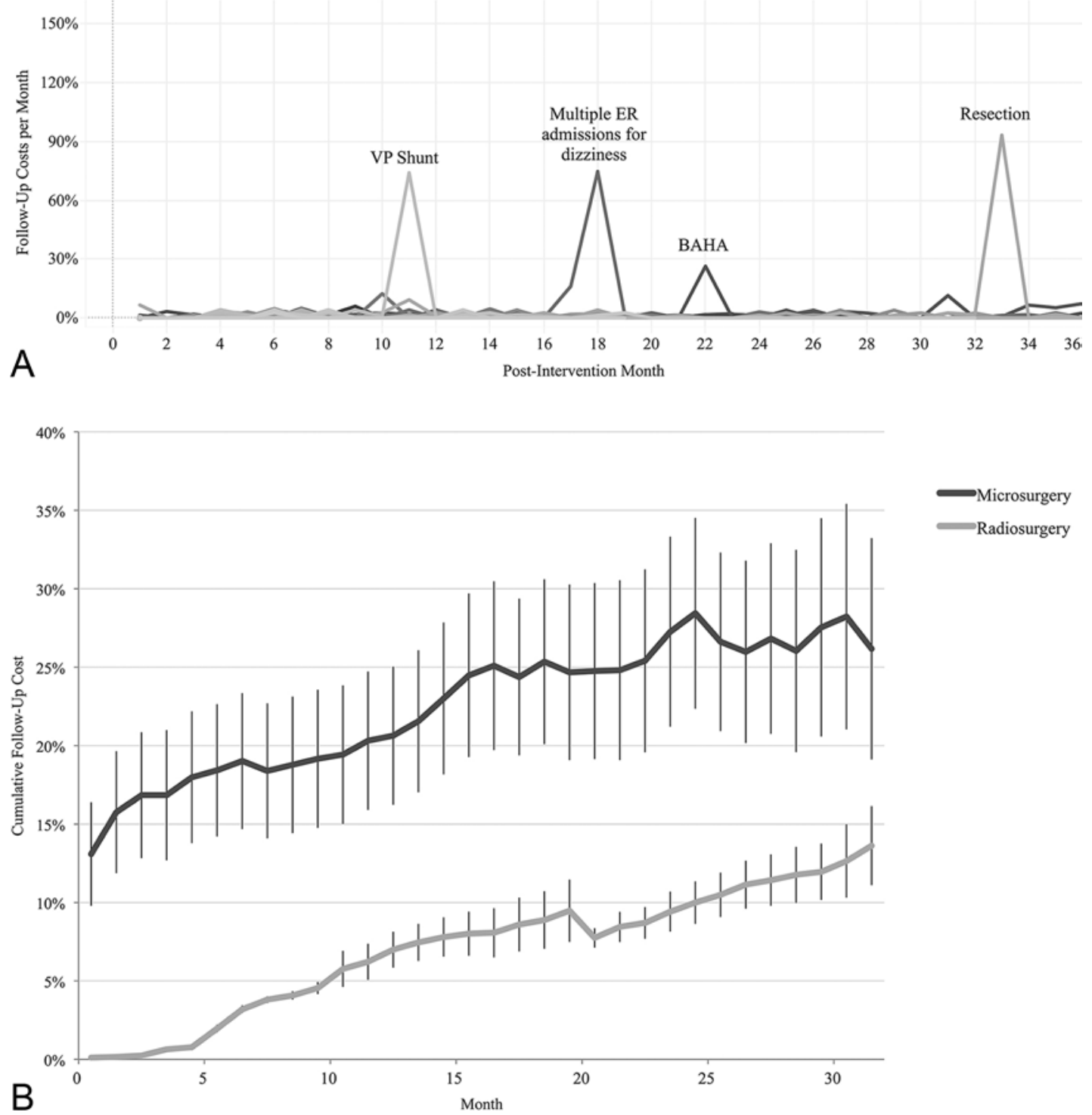

FIG. 2. A: Line graphs of follow-up costs for patients who underwent microsurgery (upper panel) and those who received radiosurgery (lower panel). Each line represents an individual patient's follow-up course. Costs are presented as a percentage of the average index cost for microsurgery. Causes of cost spikes are labeled. B: Accumulation of each month's average follow-up costs for microsurgery (black line) and radiosurgery (light gray line) with error bars demonstrating the SEM. Graph limited to 32 months because attrition results in patient numbers becoming small ( $<20$ patients for radiosurgery beyond 32 months), resulting in high uncertainty. ER = emergency room; EVD = external ventricular drain; LD = lumbar drain; VP = ventriculoperitoneal. 
TABLE 3. Additional interventions and their causes for patients who underwent MS and SRS

\begin{tabular}{|c|c|c|c|}
\hline $\begin{array}{l}\text { Complication or } \\
\text { Functional Deficit }\end{array}$ & Intervention & $\begin{array}{c}M S \\
n=203\end{array}$ & $\begin{array}{l}\text { SRS, } \\
n=114\end{array}$ \\
\hline \multirow[t]{7}{*}{$\begin{array}{l}\text { CSF leak or pseu- } \\
\text { domeningocele }\end{array}$} & & $23(11.3 \%)$ & $0(0 \%)$ \\
\hline & Lumbar drain & 14 & 0 \\
\hline & VP shunt & 2 & 0 \\
\hline & Repair & 4 & 0 \\
\hline & VP shunt $\times 3$ & 1 & 0 \\
\hline & Repair \& VP shunt & 1 & 0 \\
\hline & Repair \& lumbar drain & 1 & 0 \\
\hline \multirow[t]{3}{*}{ Hydrocephalus } & & $3(1.5 \%)$ & $1(0.9 \%)$ \\
\hline & VP shunt & 1 & 1 \\
\hline & External ventricular drain & 2 & 0 \\
\hline VS 2nd intervention & & $10(4.9 \%)$ & $1(0.9 \%)$ \\
\hline & MS & 0 & 1 \\
\hline & SRS & 10 & 0 \\
\hline \multirow[t]{3}{*}{ Wound infection } & & $3(1.5 \%)$ & $0(0 \%)$ \\
\hline & Debridement/washout & 2 & 0 \\
\hline & Debridement/washout $\times 2$ & 1 & \\
\hline \multirow[t]{3}{*}{ Meningitis } & & $5(2.5 \%)$ & $0(0 \%)$ \\
\hline & Admission for antibiotics & 4 & \\
\hline & Shunt removal & 1 & \\
\hline \multirow{3}{*}{$\begin{array}{l}\text { Hemorrhage or } \\
\text { infarction }\end{array}$} & & $2(1.0 \%)$ & $0(0 \%)$ \\
\hline & Surgical evacuation & 1 & \\
\hline & Surgical evacuation $\times 2$ & 1 & \\
\hline \multirow{7}{*}{$\begin{array}{l}\text { Facial nerve dys- } \\
\text { function }\end{array}$} & & $22(10.8 \%)$ & $0(0 \%)$ \\
\hline & Weight insertion & 13 & 0 \\
\hline & $\begin{array}{l}\text { Weight \& revision (re- } \\
\text { moval or replacement) }\end{array}$ & 4 & 0 \\
\hline & $\begin{array}{l}\text { Reconstructive eyelid } \\
\text { surgery }\end{array}$ & 0 & 1 \\
\hline & $\begin{array}{l}\text { Weight \& eyelid recon- } \\
\text { struction }\end{array}$ & 3 & 0 \\
\hline & $\begin{array}{l}\text { Reconstructive eyelid } \\
\text { surgery } \times 2\end{array}$ & 1 & 0 \\
\hline & $\begin{array}{l}\text { Hypoglossal-facial nerve } \\
\text { anastomosis \& eyelid } \\
\text { weight }\end{array}$ & 1 & 0 \\
\hline \multirow[t]{4}{*}{ Hearing loss } & & $24(11.8 \%)$ & $4(3.5 \%)$ \\
\hline & BAHA insertion & 11 & 1 \\
\hline & Other hearing aid & 12 & 3 \\
\hline & $\begin{array}{l}\text { Tympanoplast \& ossicular } \\
\text { chain reconstruction }\end{array}$ & 1 & 0 \\
\hline $\begin{array}{l}\text { Abdominal wall } \\
\text { hematoma }\end{array}$ & Surgical evacuation & $1(0.5 \%)$ & $0(0 \%)$ \\
\hline $\begin{array}{l}\text { Pain secondary to } \\
\text { BAHA }\end{array}$ & BAHA removal & $0(0 \%)$ & $1(0.9 \%)$ \\
\hline Intraop arrhythmia & Aborted procedure & $1(0.5 \%)$ & $0(0 \%)$ \\
\hline Inpatient rehab & & $17(8.4 \%)$ & $0(0 \%)$ \\
\hline
\end{tabular}

Rehab = rehabilitation; $\mathrm{VP}=$ ventriculoperitoneal . sponse to complications of treatment, such as CSF leakage, or to improve persistent functional deficits, such as insertion of a bone-anchored hearing aid (BAHA). Additional interventions and their cost impact are explored in detail in the subsection on costs drivers below.

The average cost per month of follow-up was significantly higher for the surgical cohort $(1.6 \%$ of the average index cost of microsurgery per month, SD $3.7 \%, 95 \%$ CI $0.8 \%-2.4 \%)$ compared to the radiosurgical cohort $(0.5 \%$ per month, SD $0.8 \%, 95 \%$ CI $0.4 \%-0.7 \%)(\mathrm{p}=0.009)$, and the variance was significantly larger for the surgical group ( $p<0.001$ ). As can be seen in Fig. 2A, a large share of above-normal cost spikes occurred in the first 2 months after postresection discharge from the hospital. When the initial 2 months of follow-up were excluded, there was no difference in the average cost or variance per month of follow-up for the remaining period: $0.5 \%$ per month (SD $0.6 \%, 95 \%$ CI $0.4-0.6$ ) for the surgical group and $0.6 \%$ per month (SD 0.9\%, 95\% CI 0.4-0.8) for the radiosurgical group ( $\mathrm{p}=0.44$ and $\mathrm{p}=0.53$, respectively). The takeaway effect can be seen in Fig. 2B, which demonstrates the average cumulative follow-up costs. From the outset, microsurgical follow-up costs began high due to large outlays for managing complications or inpatient rehabilitation in the first 2 months after surgery, whereas the first 2 months of follow-up costs for radiosurgery were near zero. Then cumulative costs grew nearly in parallel, because subsequent follow-up costs (standard observation with infrequent secondary interventions) were not significantly different between the groups, resulting in cumulative follow-up costs remaining larger for the surgical cohort overall.

\section{Drivers of Cost}

To assess a broad range of clinical outcomes and identify contributors to cost variance within each intervention group, the full patient sample (203 patients with microsurgery and 114 with radiosurgery) was assessed (Table 2).

\section{Additional Interventions}

Additional interventions to treat persistent functional deficits or procedure complications were assessed for all patients (Table 3). Of 203 patients who underwent microsurgery, $74(36.5 \%)$ required at least one additional intervention, with a total of 109 additional interventions between them. Of 114 patients who underwent radiosurgery, 7 (6.1\%) required at least one additional intervention, with a total of 8 interventions provided. The complication rates seen in this sample were consistent with previously reported complication rates..$^{27,29}$

When separated into subgroups by whether an additional intervention was required, patients with secondary interventions had a larger average total cost and wider variation in costs for both microsurgery and radiosurgery groups. The average total cost of the surgical subgroup requiring at least one secondary intervention was $227 \%$ (SD $167 \%, 95 \%$ CI $189 \%-266 \%$ ) of the average index cost of microsurgery, which was significantly more than the resection subgroup of patients who did not require an additional intervention (109\%, SD 33\%, 95\% CI 103\%-114\%) $(\mathrm{p}<0.001)$. For the radiosurgery group, patients who required at least one additional intervention also had a 


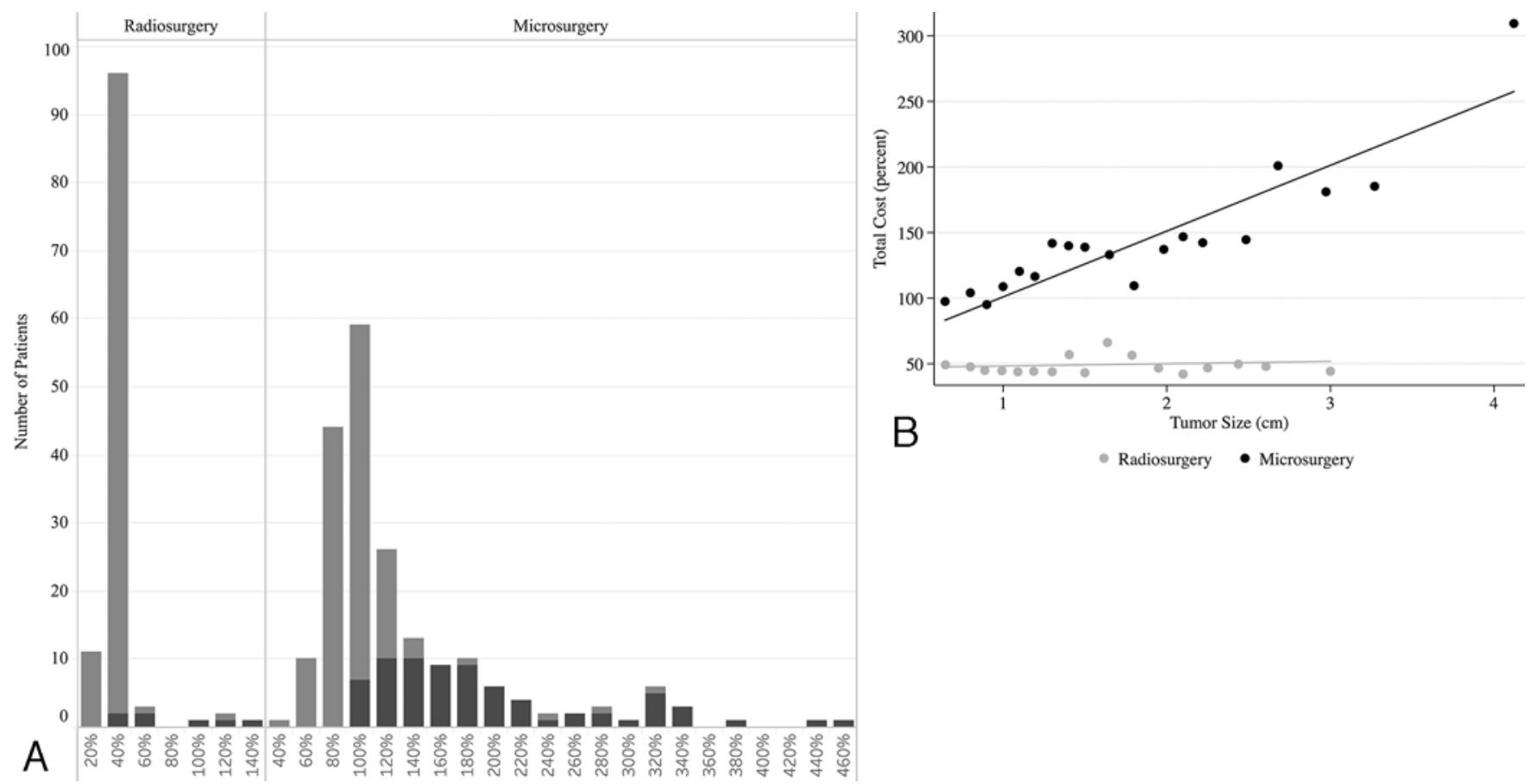

FIG. 3. A: Histograms of the number of patients per total cost (grouped in bins of $20 \%$ ). Darker gray fill indicates patients who required a secondary intervention, whereas lighter gray fill indicates no secondary intervention. Costs are presented as a percentage of the average index cost for microsurgery. Not pictured for scale purposes: 2 outlier data points in the "Microsurgery" section at $820 \%$ and $1280 \%$ bins. B: Binned scatterplots with linear regression lines for microsurgery (black) and radiosurgery (light gray). To improve visualization of large data sets, binned scatterplots group the $x$-axis variable into equal-sized bins and compute the $x$ axis and y-axis means within each bin (regression calculated from total data set). Costs are presented on the y-axis as a percentage of the average index cost for microsurgery.

higher average total cost $(92 \%$ of the average index cost of microsurgery, SD 39\%, 95\% CI 56\%-128\%) compared to patients who did not require an additional intervention (46\% of the average index cost of microsurgery, SD $10 \%$, $95 \%$ CI 44\%-48\%) (p < 0.001). Subgroups with secondary interventions had significantly larger variances compared to the subgroups without a secondary intervention for both microsurgery $(\mathrm{p}<0.001)$ and radiosurgery $(\mathrm{p}<$ 0.001) groups.

Follow-up costs led to a skewing of total cost distributions for both microsurgery and radiosurgery (Fig. 3A), with patients requiring secondary interventions disproportionately located toward the higher-cost end of the distribution. Both microsurgery (skewness 5.7, kurtosis 49.2, p $<0.001$ ) and radiosurgery (skewness 4.4, kurtosis 23.8, $\mathrm{p}<$ 0.001 ) groups demonstrated significant asymmetry in their total cost distributions with positive skews.

\section{LOS and Level of Care}

The total number of days as an inpatient, either in the hospital or in an inpatient rehabilitation facility, was very strongly correlated with total costs for patients who underwent microsurgery $(r=0.95, \mathrm{p}<0.001)$. For the majority of patients treated with microsurgery (79.8\%), all inpatient days occurred during their stay for their initial VS resection. The average index LOS was 3.9 days and was similarly correlated with index costs $(r=0.93, \mathrm{p}<0.001)$.

The most frequent postoperative course after resection for patients with VS was 1-2 days in the neurosurgical
ICU followed by 1-2 days in an acute care setting before discharge, although frequently patients were discharged directly from the ICU. On average, 2.3 days are spent in the ICU and 1.6 in an acute care setting (i.e., $58 \%$ of the index stay was spent in the ICU on average). There was no significant relationship found between index cost and the proportion of a patient's index stay spent in the ICU $(r=$ $0.02, \mathrm{p}=0.75$ ).

Of 203 patients who underwent microsurgery, 17 (8.4\%) required inpatient rehabilitation for impaired mobility, cognition, or activities of daily living. Of those patients, the average LOS at a rehabilitation facility was 15.6 days (range 2-39 days). No patients who received SRS required inpatient rehabilitation.

\section{Surgical Approach}

Of 203 surgical patients in this study, 100 (49.3\%), 90 (44.3\%), and $13(6.4 \%)$ were treated with retrosigmoid, translabyrinthine, and middle fossa approaches, respectively (Table 4). When costs associated with retrosigmoid and translabyrinthine approaches were compared, there was no difference in either average index costs $(p=0.53)$ or average total costs $(\mathrm{p}=0.51)$. Additionally, there was no difference in average LOS $(p=0.92)$ or average operating time $(p=0.66)$ for either surgical approach. In this sample, the median tumor size was larger for patients treated with the translabyrinthine approach $(2.2 \mathrm{~cm})$ than the retrosigmoid approach $(1.7 \mathrm{~cm})(\mathrm{p}=0.002)$. 


\section{Tumor Size and Other Demographics Data}

A key question of this study was the impact of tumor size on costs, as well as which factors contributed to tumor size's effect on costs. The average tumor size of the matched microsurgery group was $1.3 \mathrm{~cm}$ (Table 1), whose index cost was $100 \%$ by definition. A simple linear regression was calculated to predict total costs based on tumor size for both surgical and radiosurgical subgroups (Fig. 3B). A significant regression equation was found for surgical patients $\left(\mathrm{F}(1,201)=40.38, \mathrm{p}<0.001, \mathrm{R}^{2}=0.17\right)$, with every centimeter increase in tumor maximum diameter resulting in an estimated total cost increase of $50.2 \%$ of the average index cost of microsurgery (95\% CI $34.6 \%-$ $65.7 \%$ ). There was no significant relationship between tumor size and total cost for patients who received SRS ( $p$ $=0.55)$.

To better characterize how tumor size affects cost for resection of VS, patients were broken into subgroups based on tumor size. Several key factors were tabulated for each subgroup and the strength of their correlation with tumor size was calculated (Table 5). Index costs had a strong relationship with tumor size $(r=0.47, \mathrm{p}<0.001)$. Possible contributors underlying this correlation include the finding that larger tumors were associated with a longer LOS ( $r=$ $0.37, \mathrm{p}<0.001)$ and longer operating times $(r=0.63, \mathrm{p}<$ $0.001)$.

Although there was no difference in the average number of months followed for any tumor size subgroup $(\mathrm{p}=$ 0.25 ), there was a moderate relationship between followup costs and tumor size $(r=0.32, \mathrm{p}<0.001)$. Larger tumors were associated with more follow-up inpatient days (e.g., inpatient rehabilitation or later admission for complications) $(r=0.27, \mathrm{p}<0.001)$, a higher likelihood of at least one additional intervention $(r=0.37, \mathrm{p}<0.001)$, and a larger number of average additional interventions per patient $(r=0.43, \mathrm{p}<0.001)$.

There was a weak to moderate correlation with worse preoperative hearing (higher Gardner-Robertson grade) and total cost for patients who underwent microsurgery $(r$ $=0.22, p=0.003)$, but not for patients who received SRS $(p$ $=0.99$ ). There was no significant relationship between age and total costs for microsurgery $(p=0.19)$ or radiosurgery $(\mathrm{p}=0.21)$ subgroups.

\section{Discussion}

Newly diagnosed patients with VS may have their disease managed with observation, microsurgery, or radiosurgery. Any individual management recommendation requires consideration of the patient's specific clinical picture, demographic characteristics, and preferences.

In this study, cohorts matched for tumor size were compared, and microsurgery had significantly higher index and follow-up costs (patients were followed for 36 months). Costs should not be the primary factor in a management decision for any individual patient, because the more expensive intervention may be the most appropriate medical option. For example, microsurgery is preferred in patients who have large tumors with major symptomatic brainstem compression, even if it is more costly. Also, additional medical care that improves long-term patient outcomes or
TABLE 4. Demographic and relative costs for retrosigmoid and translabyrinthine approaches

\begin{tabular}{cccc}
\hline Variable & $\begin{array}{c}\text { Retrosigmoid } \\
(\mathrm{n}=100)\end{array}$ & $\begin{array}{c}\text { Translabyrinthine } \\
(\mathrm{n}=90)\end{array}$ & $\begin{array}{c}\mathrm{p} \\
\text { Value }\end{array}$ \\
\hline $\begin{array}{c}\text { Median tumor } \\
\text { size, cm (range) }\end{array}$ & $1.7(0.6-4.8)$ & $2.2(0.6-4.5)$ & 0.002 \\
\hline $\begin{array}{c}\text { Median age, yrs } \\
\text { (range) }\end{array}$ & $47(15-77)$ & $50(14-75)$ & 0.40 \\
\hline $\begin{array}{c}\text { Average LOS, } \\
\text { days (range) }\end{array}$ & $4.0(2-20)$ & $3.9(1-15)$ & 0.92 \\
\hline $\begin{array}{c}\text { Average op time, } \\
\text { mins (range) }\end{array}$ & $385(239-841)$ & $392(197-984)$ & 0.66 \\
\hline $\begin{array}{c}\text { Average index } \\
\text { cost (95\% Cl) }\end{array}$ & $111 \%(103 \%-120 \%)$ & $107 \%(100 \%-115 \%)$ & 0.53 \\
\hline $\begin{array}{c}\text { Average total cost } \\
(95 \% \text { Cl) }\end{array}$ & $161 \%(131 \%-190 \%)$ & $149 \%(132 \%-166 \%)$ & 0.51 \\
\hline
\end{tabular}

Costs are presented as a percentage of the average MS index cost.

quality of life, such as rehabilitation and hearing aids, ${ }^{1,18}$ should not be restricted because of added costs.

Still, under circumstances in which management approaches offer equivalent clinical outcomes, costs can be one factor to differentiate care choices, and cost reduction strategies that do not harm patient care can positively inform clinical practice.

\section{VS Cost Reduction Strategies}

One cost reduction strategy that has been pursued for decades is reducing the number of days a patient stays as an inpatient and shifting costs from hospital acute care to outpatient care. ${ }^{26}$ The findings in this study support these efforts, given that LOS had a strong correlation with total costs. Strategies to avoid unnecessary inpatient days for VS resection include prioritizing outpatient preoperative work-ups rather than direct from emergency room admissions and avoiding additional days for surgical addons if the secondary procedure, such as insertion of an eyelid gold weight, could be performed in a day surgery setting.

Another frequently promoted cost reduction effort is the more rapid transfer of patients to an acute care unit to reduce the number of days a patient spends in the ICU. ${ }^{34}$ However, the proportion of inpatient days in the ICU was not associated with cost savings in this study. This result is supported by other study findings that have demonstrated that transfer to an acute care unit results in only small marginal cost savings. ${ }^{11}$ Additionally, one of the largest contributors to ICU costs is mechanical ventilation, ${ }^{5}$ which is rarely required beyond the day of operation for patients with VS. These findings emphasize that, for patients who undergo microsurgery for VS, reducing total inpatient days is more important than rapidly transferring patients to acute care units.

One previous retrospective investigation indicated that patients undergoing the retrosigmoid approach had higher costs with longer hospital stays than patients treated with the translabyrinthine approach. ${ }^{28}$ We found no cost difference between these surgical approaches, and no difference 
TABLE 5. Tumor size subgroup results and correlation for patients who underwent MS

\begin{tabular}{|c|c|c|c|c|c|c|c|}
\hline \multirow[b]{2}{*}{ Subgroup Tabulation } & \multicolumn{5}{|c|}{ Max Tumor Diameter (no. of patients) } & \multicolumn{2}{|c|}{$\begin{array}{c}\text { Correlation w/ } \\
\text { Tumor Size }\end{array}$} \\
\hline & $<1 \mathrm{~cm}(\mathrm{n}=23)$ & $1-2 \mathrm{~cm}(\mathrm{n}=80)$ & $2-3 \mathrm{~cm}(\mathrm{n}=58)$ & $3-4 \mathrm{~cm}(\mathrm{n}=31)$ & $4-5 \mathrm{~cm}(\mathrm{n}=11)$ & r & p Value \\
\hline Relative total cost & $99 \%$ & $125 \%$ & $154 \%$ & $189 \%$ & $340 \%$ & 0.41 & $<0.001$ \\
\hline Relative index cost & $85 \%$ & $101 \%$ & $103 \%$ & $127 \%$ & $184 \%$ & 0.47 & $<0.001$ \\
\hline LOS, days (index) & 2.9 & 3.6 & 3.6 & 4.4 & 8.4 & 0.37 & $<0.001$ \\
\hline Op time, mins (index case) & 301 & 339 & 390 & 516 & 492 & 0.63 & $<0.001$ \\
\hline Relative follow-up costs & $14 \%$ & $24 \%$ & $51 \%$ & $61 \%$ & $154 \%$ & 0.32 & $<0.001$ \\
\hline LOS, days (follow-up) & 0.3 & 1.1 & 3.1 & 3.8 & 10.0 & 0.27 & $<0.001$ \\
\hline Patients w/ secondary intervention & $4 \%$ & $25 \%$ & $47 \%$ & $55 \%$ & $82 \%$ & 0.37 & $<0.001$ \\
\hline Average no. of secondary interventions & 0.04 & 0.28 & 0.66 & 1.00 & 1.55 & 0.43 & $<0.001$ \\
\hline
\end{tabular}

Costs are presented as a percentage of the average MS index cost.

between the LOS or operating times (Table 4). The difference in findings may be due to different hospital care regimens, but our study underlines that neither surgical approach is inherently more costly than the other.

The finding that larger tumors resulted in higher microsurgical costs informs consideration of the wait-andscan option for initial VS. Although it has been previously argued that observational costs over decades can grow to exceed radiosurgical costs, ${ }^{35}$ this may understate the true cost of observation. Accurately measuring tumor growth is challenging given the difficulty of differentiating 1to $2-\mathrm{mm}$ changes in a single imaging plane, but reports have indicated that most VSs grow at rates of $1-3 \mathrm{~mm}$ per year in at least one plane. ${ }^{14}$ Seventy percent of patients have measurable tumor growth within 5 years and $95 \%$ demonstrate growth by 10 years. ${ }^{14}$ Given the potential for continued tumor growth, the additional costs of surgical intervention, if required, could be attributable to the waitand-scan approach. Future investigation is required to fully characterize the costs of observation.

\section{Study Limitations}

There are several limitations of this study. All cost data were derived from a single institution, potentially limiting generalizability given that institutional factors-including location, size, and management-affect cost. Additionally, the studied institution has significant experience with treating VS with both microsurgery and radiosurgery, and less experienced centers may have different complication rates or LOSs.

Another study limitation is that it only evaluated costs through 36 months and had an average follow-up of only approximately 25 months. It is possible that additional costs could accrue beyond the time period studied, such as costs for post-SRS or postresection surgical interventions or hearing augmentation procedures or devices. Also, no societal costs, such as lost wages attributable to recovery time or disability, were considered. Future investigations are needed to fully characterize long-term and societal costs.

\section{Conclusions}

This study is the largest assessment to date based on real hospital cost data comparing VS management with microsurgery and radiosurgery. Despite limitations, several findings inform VS management approaches and potential cost reduction strategies.

For a cohort of patients with unilateral VS matched for tumor size, costs of the microsurgery subgroup were significantly higher and demonstrated more variability than those of the radiosurgery subgroup, in both index and follow-up costs. Additional interventions in the followup period, undertaken due to complications or persistent functional deficits, were a major driver of costs for both resection and radiosurgery.

Costs of patients treated with microsurgery were also driven by length of inpatient stay and patient demographics. In particular, larger tumor size was associated with increased surgical costs. There were no cost differences associated with the proportion of inpatient days in the ICU or with the specific surgical approach.

\section{References}

1. Arunachalam PS, Kilby D, Meikle D, Davison T, Johnson IJ: Bone-anchored hearing aid quality of life assessed by Glasgow Benefit Inventory. Laryngoscope 111:1260-1263, 2001

2. Banerjee R, Moriarty JP, Foote RL, Pollock BE: Comparison of the surgical and follow-up costs associated with microsurgical resection and stereotactic radiosurgery for vestibular schwannoma. J Neurosurg 108:1220-1224, 2008

3. Breivik CN, Nilsen RM, Myrseth E, Pedersen PH, Varughese JK, Chaudhry AA, et al: Conservative management or gamma knife radiosurgery for vestibular schwannoma: tumor growth, symptoms, and quality of life. Neurosurgery 73:48-57, 2013

4. Brook RH: The role of physicians in controlling medical care costs and reducing waste. JAMA 306:650-651, 2011

5. Dasta JF, McLaughlin TP, Mody SH, Piech CT: Daily cost of an intensive care unit day: the contribution of mechanical ventilation. Crit Care Med 33:1266-1271, 2005

6. Emanuel EJ, Fuchs VR: Who really pays for health care? The myth of "shared responsibility". JAMA 299:1057-1059, 2008

7. Gait C, Frew EJ, Martin TP, Jowett S, Irving R: Conservative management, surgery and radiosurgery for treatment of vestibular schwannomas: a model-based approach to costeffectiveness. Clin Otolaryngol 39:22-31, 2014

8. Golfinos JG, Hill TC, Rokosh R, Choudhry O, Shinseki M, Mansouri A, et al: A matched cohort comparison of clinical 
outcomes following microsurgical resection or stereotactic radiosurgery for patients with small- and medium-sized vestibular schwannomas. J Neurosurg 125:1472-1482, 2016

9. Hoistad DL, Melnik G, Mamikoglu B, Battista R, O'Connor CA, Wiet RJ: Update on conservative management of acoustic neuroma. Otol Neurotol 22:682-685, 2001

10. International RadioSurgery Association: Radiosurgery Practice Guideline Initiative. Stereotactic Radiosurgery for Patients with Vestibular Schwannomas. Harrisburg, PA: ISRA, 2006 (http://www.irsa.org/AN\%20Guideline.pdf) [Accessed July 17, 2018]

11. Kahn JM, Rubenfeld GD, Rohrbach J, Fuchs BD: Cost savings attributable to reductions in intensive care unit length of stay for mechanically ventilated patients. Med Care 46:1226-1233, 2008

12. Karpinos M, Teh BS, Zeck O, Carpenter LS, Phan C, Mai WY, et al: Treatment of acoustic neuroma: stereotactic radiosurgery vs. microsurgery. Int J Radiat Oncol Biol Phys 54:1410-1421, 2002

13. Kentala E, Pyykkö I: Clinical picture of vestibular schwannoma. Auris Nasus Larynx 28:15-22, 2001

14. Kondziolka D, Mousavi SH, Kano H, Flickinger JC, Lunsford LD: The newly diagnosed vestibular schwannoma: radiosurgery, resection, or observation? Neurosurg Focus 33(3):E8, 2012

15. Levinsky NG: The doctor's master. N Engl J Med 311:15731575,1984

16. Matthies C, Samii M: Management of 1000 vestibular schwannomas (acoustic neuromas): clinical presentation. Neurosurgery 40:1-10, 1997

17. Muennig P: Cost-Effectiveness Analyses in Health: A Practical Approach, ed 2. San Francisco: Jossey-Bass, 2008

18. Mulrow CD, Aguilar C, Endicott JE, Tuley MR, Velez R, Charlip WS, et al: Quality-of-life changes and hearing impairment. A randomized trial. Ann Intern Med 113:188194, 1990

19. Myrseth E, Møller P, Pedersen PH, Lund-Johansen M: Vestibular schwannoma: surgery or gamma knife radiosurgery? A prospective, nonrandomized study. Neurosurgery 64:654-663, 2009

20. Myrseth E, Møller P, Pedersen PH, Vassbotn FS, WentzelLarsen T, Lund-Johansen M: Vestibular schwannomas: clinical results and quality of life after microsurgery or gamma knife radiosurgery. Neurosurgery 56:927-935, 2005

21. Nikolopoulos TP, O'Donoghue GM: Acoustic neuroma management: an evidence-based medicine approach. Otol Neurotol 23:534-541, 2002

22. Peden AH (ed): Comparative Health Information Management. Clifton Park, NY: Cengage Learning, 2012

23. Pollock BE, Driscoll CL, Foote RL, Link MJ, Gorman DA, Bauch CD, et al: Patient outcomes after vestibular schwannoma management: a prospective comparison of microsurgical resection and stereotactic radiosurgery. Neurosurgery 59:77-85, 2006

24. Pollock BE, Lunsford LD, Kondziolka D, Flickinger JC, Bissonette DJ, Kelsey SF, et al: Outcome analysis of acoustic neuroma management: a comparison of microsurgery and stereotactic radiosurgery. Neurosurgery 36:215-229, 1995

25. Régis J, Pellet W, Delsanti C, Dufour H, Roche PH, Thomassin JM, et al: Functional outcome after gamma knife surgery or microsurgery for vestibular schwannomas. J Neurosurg 97:1091-1100, 2002
26. Robinson JC: Decline in hospital utilization and cost inflation under managed care in California. JAMA 276:1060-1064, 1996

27. Samii M, Matthies C: Management of 1000 vestibular schwannomas (acoustic neuromas): surgical management and results with an emphasis on complications and how to avoid them. Neurosurgery 40:11-23, 1997

28. Semaan MT, Wick CC, Kinder KJ, Stuyt JG, Chota RL, Megerian CA: Retrosigmoid versus translabyrinthine approach to acoustic neuroma resection: A comparative costeffectiveness analysis. Laryngoscope 126 (Suppl 3):S5-S12, 2016

29. Slattery WH III, Francis S, House KC: Perioperative morbidity of acoustic neuroma surgery. Otol Neurotol 22:895-902, 2001

30. Sonig A, Khan IS, Wadhwa R, Thakur JD, Nanda A: The impact of comorbidities, regional trends, and hospital factors on discharge dispositions and hospital costs after acoustic neuroma microsurgery: a United States nationwide inpatient data sample study (2005-2009). Neurosurg Focus 33(3):E3, 2012

31. Sulmasy DP: Physicians, cost control, and ethics. Ann Intern Med 116:920-926, 1992

32. Whitmore RG, Urban C, Church E, Ruckenstein M, Stein SC, Lee JY: Decision analysis of treatment options for vestibular schwannoma. J Neurosurg 114:400-413, 2011

33. Young DW: The folly of using RCCs and RVUs for intermediate product costing. Healthc Financ Manage 61:100-106, 2007

34. Zimmerman JE: Intensive care unit length of stay: can it be reduced? Crit Care Med 27:1393-1394, 1999

35. Zygourakis CC, Oh T, Sun MZ, Barani I, Kahn JG, Parsa AT: Surgery is cost-effective treatment for young patients with vestibular schwannomas: decision tree modeling of surgery, radiation, and observation. Neurosurg Focus 37(5):E8, 2014

\section{Disclosures}

Dr. Kondziolka received support from Brainlab for a non-studyrelated clinical or research effort that he oversees.

\section{Author Contributions}

Conception and design: Kondziolka, Schnurman, Golfinos, Friedmann, Roland. Acquisition of data: Schnurman, Epstein. Analysis and interpretation of data: all authors. Drafting the article: Kondziolka, Schnurman, Golfinos, Friedmann, Roland. Critically revising the article: Kondziolka, Schnurman, Golfinos, Friedmann, Roland. Reviewed submitted version of manuscript: Kondziolka, Schnurman, Golfinos, Friedmann, Roland. Approved the final version of the manuscript on behalf of all authors: Kondziolka. Statistical analysis: Schnurman. Administrative/technical/material support: Kondziolka, Golfinos. Study supervision: Kondziolka, Golfinos.

\section{Correspondence}

Douglas Kondziolka: NYU Langone Medical Center, New York, NY. douglas.kondziolka@nyumc.org. 